\title{
The Equality of Lotteries
}

\author{
BEN SAUNDERS
}

\begin{abstract}
Lotteries have long been used to resolve competing claims, yet their recent implementation to allocate school places in Brighton and Hove, England led to considerable public outcry. This article argues that, given appropriate selection is impossible when parties have equal claims, a lottery is preferable to an auction because it excludes unjust influences. Three forms of contractualism are discussed and the fairness of lotteries is traced to the fact that they give each person an equal chance, as a surrogate for their equal claim to the good. It is argued that this can be a reason to favour an artificially-constructed lottery to a 'natural' lottery where there is suspicion that the latter may be biased.
\end{abstract}

The recent decision by Brighton and Hove council to allow allocation of school places by lottery has drawn much controversy, both in the popular media and the pages of this journal. ${ }^{1}$ As an advocate of lotteries in various distributive contexts, I would like here to defend the justice of lotteries when it comes to distributing non-divisible, scarce goods - such as school places, jobs or organs - between equal claimants. I do so by considering three possible distributive procedures - selection, auction and lottery - and three forms of contractualist justification - those of Harsanyi, Rawls and Scanlon - as well as the specific issues arising in the case of distributing school places.

\section{The Need for Distribution and Three Methods}

One reason to employ a lottery is that it gives each party an equal chance of obtaining the good in question. This leads some to assume that a lottery is ultimately required by that most elusive of

1 A. O’Hear, 'Editorial: The Equality Lottery', Philosophy 82, No. 2 (April 2007), 209-10. For examples of mass media debate, see G. Paton 'Schools can use lotteries for 'fairer' admissions, says minister', The Daily Telegraph (Thursday 01/03/07) 15, and S. Laville and R. Smithers 'War over school boundaries divides Brighton', The Guardian (Thursday 01/ $03 / 07), 4$. 


\section{Ben Saunders}

social goals, equal opportunity. ${ }^{2}$ My defence will not appeal to such broader social goals. Rather, I think lotteries can be justified as tiebreakers between equally-strong but competing claims to goods in scarce supply. On this account, although the lottery is justified because it gives each party an equal chance of receiving the good in question, this is not seen as an end in itself - equality of opportunity but merely a surrogate satisfaction, second-best to getting the good. ${ }^{3}$ If our aim was simply equality of opportunity, then we would not find anything problematic in the lottery. The fact that many are uneasy with lotteries is, I believe, because we really want equality of outcome - the same education for everyone - and so we are unhappy with the idea that some, even when selected by some fair random procedure, receive better than others; even though we prefer this all-things-considered to levelling down. ${ }^{4}$

Suppose we have a single good and two parties with equal claims to it, whatever it is that grounds those claims. The ideal distribution, between two equal claimants, is half-half. For goods which are divisible, such as a cake, this distribution is feasible and various procedures can be designed to implement it (for example, one cuts the cake and the other chooses). Of course, not all goods can be literally cut in half like this, as illustrated by the Biblical story of Solomon half a baby is no use to anyone, and the real mother would rather surrender her claim than have her child cut in half. ${ }^{5}$ Sometimes, however, goods that cannot literally be cut in half can still be shared in other ways - for example, two parties might enjoy use of a parking place on alternate days or otherwise divide the various rights of ownership. There are, however, indivisible goods that cannot be shared in any sense and for which any allocation is necessarily 'winner takes all'. This seems to be the case with school places and scarce medical organs - it would hardly be practical to swap children between schools on alternate days or even weeks, much less

2 The confusion surrounding equality of opportunity is well-exposed in J.R. Richards, 'Equality of Opportunity', Ratio X, No. 3 (December 1997), 253-79. It is equality of opportunity, rather than lotteries per se, that seems to motivate O'Hear's complaint.

3 For others who stress the second-best nature of lotteries, see J. Broome 'Fairness' in his Ethics Out of Economics (Cambridge: Cambridge University Press, 1999), 119-21, and P. Stone 'Why Lotteries Are Just', The Fournal of Political Philosophy 15, No. 3 (September 2007), 284 and 294.

4 D. Parfit, 'Equality', Ratio X, No. 3 (December 1997), 211 and passim.

1 Kings 3:16-28 
transplant organs. The difficult question for distributors is what to do in these cases.

The only way to ensure retrospective equality is, seemingly, to give the good to no-one, which is the only policy ensuring that neither party receives more than the other for no reason. ${ }^{6}$ If we assume, however, that what is to be distributed is indeed a good - that is, that parties are better off if they have more of it - then this seems a gratuitous waste. There may be some goods that matter only positionally and where we are willing to make some worse off simply for the sake of equality. ${ }^{7}$ For most goods in most contexts, however, overall utility trumps equality in an all-things-considered judgement. Suppose we are not willing to reduce the total amount of good available, simply to ensure that none have more than others. In that case, we have to give the good to someone, but the question remains how it is to be distributed. Three distributive mechanisms seem particularly prominent:

(i) Selection, i.e. allocation according to some relevant criterion,

(ii) Auction, i.e. bestowing the good on the highest bidder, or

(iii) Lottery, i.e. a random allocation.

While all three principles have some place in distributing goods within a large, mixed economy, I think lotteries are uniquely appropriate in the case of allocating school places between children with equal claims. Before arguing this, and then turning to the normative justification of lotteries, however, some further comments on each mechanism are in order.

\section{i) Selection}

Some goods are possessed of a certain meaning or importance, either intrinsically or in virtue of social understandings, which can provide a criterion of distribution. ${ }^{8}$ In the case of medical resources, for example, the aim is health, and so it seems appropriate that organs

6 Broome, op. cit., 119.

7 Richards, op. cit., 217 offers the example of running shoes in a race. If only half the competitors have shoes, it seems fair to make all run barefoot.

For examples of such claims, see B. Williams, 'The Idea of Equality' in his Problems of the Self: Collected Papers 1956-72 (Cambridge: Cambridge University Press, 1973), 240-1 and M. Walzer, Spheres of Fustice: A Defence of Pluralism and Equality (Oxford: Blackwell, 1983), passim. 


\section{Ben Saunders}

go to those whose need is greatest or most urgent. If the purpose of education is learning, then arguably school places should go to those willing and able to learn, and thus selective testing seems a fair way to distribute benefits. The problem with this approach, however, is that it seems to deny the premise that we have two parties with equal claims to begin with. While it may make sense to say that two parties can equally have a claim to something, though those claims differ in some fashion - for instance, if it is said all equally have a right to life, though that life may differ in quality or length - to then use these differences to discriminate between supposedly equal claimants is either to say that their claims were not equal after all, for the strength of the claim actually depends on these differences, or it is to unjustly favour one of the equal claims over the other on the basis of irrelevant differences. It may be that those who could benefit more from an elite education or organ transplant do and should have a stronger claim to it, but that is no help in discriminating between those whose claims are ex hypothesi equal. If we assume that we are dealing with a comprehensive school and children of about average academic ability, then selection is no help.

\section{ii) Auction}

An alternative way of distributing a good between those of equal claims is to hold an auction, where the good goes to the highest bidder. This market solution seems to encourage a form of efficiency, if we assume that the one who wants the good more will be willing to pay more for it. Moreover, it can also be used to restore a form of equality, if we use the winning bid to compensate the loser - which could be seen as the winner buying out the other's $50 \%$ stake in the good. This approach seems most defensible to me in cases where the 'claim' each side has is really a liberty-right to the good, rather than a claim-right in the Hohfeldian sense. ${ }^{9}$ For instance, if the two of us find a casket washed up on the beach, and cannot agree which of us should have it, then it seems fair for me to buy out your claim. If what is at stake is, however, something parties really have a right to in the strong sense, then it is not always clear that it should be allocated by market norms - it may be objectionable,

9 For discussion of Hohfeld's influential classification, see J. J. Thomson, The Realm of Rights (Cambridge, Mass.: Harvard University Press, 1990), ch.1 and L. W. Sumner, The Moral Foundation of Rights (Oxford: Clarendon Press, 1987), ch.2. 
for example, that the rich are able to buy themselves longer lives. Further, the problem in any real-world context is that people are not equally-placed to bid for what they want. A needed organ, for example, may be equally as important - perhaps more so - to the poor man than the rich one, but he may simply be unable to afford to match the latter's bid. Whatever the merits of an auction in a world that already has a just distribution of resources, market exchanges merely preserve the equality or inequality of the initial distribution, so an auction is no longer fair in a world marked by unjust inequality in wealth.

\section{iii) Lottery}

The third possible means of allocation is to distribute the good by lottery, by which I mean an unpredictable, random process giving each party an equal chance of receiving the good. ${ }^{10}$ I will not, here, go in to the details of what constitutes a lottery or what distinguishes a fair one from an unfair one; hopefully a few brief remarks will suffice. The lottery has to give equal claimants equal chances, but these chances need only be epistemic probabilities. It is enough that parties have no warranted belief that either outcome is more likely, as we can see it does not matter if a coin has already been flipped, secretly, and covered before one person calls. At this stage, the outcome is already either heads or tails and there is no objective probability of the other, but since the epistemic probabilities are still 50-50 the lottery is a fair one. Note that it is a consequence of this reasoning that a biased coin can be used in a fair lottery provided that the caller does not know it is biased or, at least, which way it is biased, it does not matter that the coin is objectively more likely to land on one side than the other. ${ }^{11}$

10 Technically the 'equal chance' criterion assumes this is a fair lottery. A fair lottery is one where each side has an equal chance of winning. A just lottery is one that is appropriate to resolve a given conflict. A fair lottery need not be just, for instance if we were to toss a fair coin between two very unequal claimants. I do not here consider the merits of a weighted lottery, but possibly one may be just though not fair, as I use the term here.

11 Of course, a fair coin is generally preferable to a biased one, if only to remove any suspicion that the bias was known. In principle, however, if a third-party coin-tosser informed the claimants beforehand that he was using a biased coin, it should make no difference to the fairness of the lottery. 


\section{Ben Saunders}

All three distributive criteria seem to have some role to play in society. As already pointed out, however, the first seems not to be a way of adjudicating between equal claims, but rather a way of measuring the strength of claims. It is entirely possible to say that those of greater academic ability or potential have a greater claim to academic resources, and academic selection may be used to sort some pupils into selective schools at either the top or bottom end of the spectrum (grammar schools or special needs, respectively). If selection determines the strength of claims, it cannot however be used to break ties between equal claims. This leaves us with the possibilities of auctions or lotteries. Auctioning school places, I think, would be particularly problematic given both inequality in wealth and the fact that it would place children at the mercy of what their parents were willing and able to pay. It seems, then, that some sort of lottery is preferable to either of the alternatives. The question is whether the lottery need involve the explicit and deliberate use of an artificial randomizing device or whether we can use some other factor, such as geographical proximity, as a 'natural lottery'. ${ }^{12}$ The answer to this will only become clear when we consider what it is that justifies the use of a lottery in the first place.

\section{Three Versions of Contract Theory and Equal Chances}

One influential way of determining the morality of a certain course of action has been to appeal to the moral rules that would be agreed by suitably-placed contractors, which seems to be one way of operationalizing something like Kant's generalizability requirement. While specification of the contract conditions varies, a standard way of applying this procedure is to ask what people would accept if they did not know who they were going to be, a restriction that rules out any improper

12 By a 'natural lottery' I mean letting goods fall where they lie, on the assumption that this is at least epistemically random. Thus, for example, if some good is falling towards us, we may agree that whoever it lands closest to should keep it, rather than adopting some further artificial chance mechanism. I do not mean a constitutive lottery, as Rawls intends by the term, see J. Rawls, A Theory of Fustice revised edition (Oxford: Oxford University Press, 1999), 64 and S. Hurley, Fustice, Luck, and Knowledge (2003), ch.4. I address the question whether geographical proximity really can serve as a natural lottery below. 


\section{The Equality of Lotteries}

personal bias. The question is whether such a procedure can justify the use of lotteries. It has recently been claimed that many forms of contractualism are unable to justify lotteries, ${ }^{13}$ but this is something that I wish to challenge. The use of lotteries, and acceptance of their fairness, is so widespread that I would regard it as a serious blow against any proposed normative theory if it could not at least allow for their use. I shall consider three particular contract theories, namely those of Harsanyi, Rawls and Scanlon.

\section{i) Harsanyi}

The first theory I consider is Harsanyi's argument for average utilitarianism. ${ }^{14}$ Harsanyi proposes that we should adopt as 'ethical preferences' those we would have if we had an equal probability of being any person in society, as if some sort of disembodied identity-bearing soul was randomly-allocated to each particular body. If each person in some original position had an equal chance of being anybody in society, then they would consider each person's interests equally, and they would maximize their own expected interest by choosing the social policy leading to highest average utility. Suppose, for example, it is suggested that we redistribute some wealth from the rich to the poor, on the grounds that the poor will derive more utility from this money. Though as a matter of fact the rich know that this will make them financially worse off, if they were to regard the society from the outside, and suppose they were to have an equal chance of being anyone in it, then they would prefer the more equal society, and we should take this unbiased preference as an ethical judgement.

13 Stone, op. cit., 289-91. I will not, in the following, discuss Gauthier's version of contractarianism, which seems less plausible (to me) than the three I do discuss; but I see no reason why it cannot lead to lotteries, at least to adjudicate between parties with equal bargaining strength.

14 J. Harsanyi, 'Cardinal Utility in Welfare Economics and in the Theory of Risk-taking', Fournal of Political Economy, 61, No. 5 (October 1953), 434-5 and 'Cardinal Welfare, Individualistic Ethics, and Interpersonal Comparisons of Utility', Fournal of Political Economy, 63, No. 4 (August 1955), 314-5. Stone, op. cit., 282, contrasts Harsanyi's contractarian account of justice to utilitarianism. I see utilitarianism as a firstorder moral theory, and contractarianism a meta-theory by which it may be justified. C.f. T. M. Scanlon 'Contractualism and Utilitarianism' in Utilitarianism and Beyond, B. Williams and A. Sen (eds.) (Cambridge: Cambridge University Press, 1982). 


\section{Ben Saunders}

While this example shows that the demands of Harsanyi's theory, like any utilitarianism, may coincide with justice, this is only contingent. In this example, it is supposed that equality promotes an increase in utility because of diminishing marginal utility, but it is the increase in utility that does the normative work. Suppose instead that the marginal utility of money actually increases, as people are able to buy ever more extravagant luxuries. In this case, Harsanyi's theory favours more inequality. If it is so much better to be super-rich than comfortably off, then one would prefer a 50-50 chance of being super-rich or destitute to the certainty of being merely comfortable. Thus Harsanyi's theory, like any utilitarianism, is compatible with extreme, and undeserved, inequality.

Moreover, Harsanyi's theory seems compatible not only with inequality but discrimination. Suppose we have two children competing for a single school place, both equal in all relevant respects, but one white and the other black. On Harsanyi's theory, it would seem just for the school to adopt a policy of admitting the white child, and no-one could complain that this was discriminatory if they assumed they had an equal chance of being either the white or the black child! As Stone observes, if each person supposes they have a $1 / m$ chance of being in any position in society, then any policy adopted - whether a fair lottery or a racially-discriminatory one such as this - gives them a $1 / m$ chance of getting the job. It seems, therefore, that there is no reason, on Harsanyi's proposal, to adopt a lottery. ${ }^{15}$ The reason, however, is not blindness to the fairness of such, but the assumption that a randomization has already taken place. If we really did have an equal chance of being either the white or the black child, then this might be an unobjectionable form of 'natural lottery'. The problem, as I will come to in the next sub-section, is that this assumption is simply not true - we do not really have an equal chance of being anyone, but are already concrete persons with particular characteristics, such as skin colour.

15 Stone, op. cit., 290. Or, at least, no reason of justice. There are two possible reasons why a lottery may be favoured: a) because people value being treated fairly, and therefore even losers have a higher utility if they know a lottery was held and b) if what is to be chosen is a general social policy, rather than decision for a particular case, then one cannot be sure that a rule like 'pick the white candidate' will select one and only one person for the job, whereas allocating the $\operatorname{good}(\mathrm{s})$ by lottery is a perfectly general procedure. 


\section{The Equality of Lotteries}

\section{ii) Rawls}

John Rawls offers a refinement of Harsanyi's theory, using the similar device of an 'original position' to argue for more stringent principles of justice that include priority to the worst-off. Rather than literally assuming equiprobability, he put the agents under a 'veil of ignorance' that excluded knowledge of all irrelevant personal information. Further, contractors were explicitly prevented from gambling on outcomes by being denied all knowledge of probabilities and required to choose principles that they could live by for all time. ${ }^{16}$ Does this variation on Harsanyi's proposal generate any reason to use a lottery?

Consider again the case of the white and black children. If both were in Rawls' original position, with no knowledge either of their skin colour or their chances of being either white or black, it might still seem reasonable for them to agree to a discriminatory policy just as it is perfectly reasonable to use a biased coin, provided that one does not know which way it is biased. In this way, they use an arbitrary natural fact as a natural lottery, rather than requiring artificial randomization. But would this really be agreed to in the original position? I think not, for two reasons:

a) Rawls argues that it is rational for parties to adopt a maximin policy, making the worst-off as well-off as possible. I shall not here question either whether this conclusion really does follow from Rawls' premises or whether the import of this derivation is diminished by Rawls specifying the original position so that this conclusion follows. Assuming it is the case that parties will try to maximize the position of the worst-off, this seems to give them reason to prefer a lottery to an arbitrary allocation. Stone assumes that, either way, the worst outcome is the same - not getting the job - and thus parties would be indifferent about a lottery. I believe the chance of a benefit is itself a benefit; after all, almost everyone prefers to have a chance rather than none. If the chance of a benefit is indeed itself a benefit, then parties would prefer a lottery to having no chance. What's more, maximin would require us to maximize

16 Rawls, op. cit., for example, 11-2 and 153-4. Stone, op. cit., 291, claims contractors in such a framework would have no special reason to favour lotteries, though Rawls explicitly recommends lotteries in a number of places, e.g. Rawls, op. cit., 329 and 'Outline of a Decision Procedure for Ethics', The Philosophical Review, 60, No. 2 (April 1951), 193. I argue below that lotteries can indeed be recommended from Rawls' original position. 


\section{Ben Saunders}

the worst-off person's chances or, in other words, require equal chances or a fair lottery. ${ }^{17}$

b) Contractors are required to adopt principles that they and their descendents could live by in good faith. ${ }^{18}$ It seems that this gives them another reason to consider the position that they will be in once the veil of ignorance is lifted. While, from the original position, one has no knowledge of one's skin colour and therefore seems to be entering a lottery, once one finds that one is in fact black it would, I contend, be impossible to live with a society in which racial discrimination was the norm. While it seems as if Rawls' original position effectively adopts the standpoint of an impartial observer rather than considering different viewpoints, a charitable interpretation can allow that original contractors will attach importance to the particular perspective they will have when the veil is lifted.

While it may seem prima facie reasonable for contractors to accept the result of a natural lottery, that is not in fact so when the natural lottery is tied to something constitutive of either party's identity. Compare two cases of a natural lottery, the first where some mannalike good literally falls from the sky, and could land on either one of us, and the second where a good is attached to an arbitrary natural fact about persons, such as skin colour. We could accept the outcome of the former as just - since we have no reason to believe that the manna is more likely to fall on either one of us, there is no need to insist on a further, artificial randomization rather than letting the good fall where it happens to. The latter, however, is unacceptable because concretely-situated persons could not accept it, and so this gives parties in the original position - with an eye to what they could later live by - reason to reject it. This leads me to discuss the third form of contractualism.

17 Stone, op. cit., 291. He dismisses this response in footnote 29, but I confess to finding the reasoning obscure. Of course, that the chance of a benefit is itself a benefit is disputed. I cannot here argue for this belief, but point to the considerations in Richards, op. cit., 271-4.

18 A requirement Rawls, (1999) op. cit., 153-4, refers to as the 'strains of commitment'. Note that this consideration comes in because Rawls explicitly uses the original position to determine general principles to regulate the basic structure of society. There is no suggestion that similar reasoning applied directly to particular problems will lead to satisfactory conclusions. 


\section{The Equality of Lotteries}

\section{iii) Scanlon}

Scanlon by-passes any appeal to an original position or choice under uncertainty, insisting instead that what matters is reasonable agreement by situated parties. ${ }^{19}$ While, in actual society, a white person may well propose a racist school admissions policy, and a black person may even accept such, perhaps due to an internalized inferiority complex or inferior bargaining position, this simple empirical fact is rightly taken to be of no normative significance. What is relevant is that the white person could not reasonably insist on a racist admissions policy and the black person could reasonably reject any such proposal. The idea that, from some prior abstract position, skin colour is a natural lottery is irrelevant to the actual perspectives of concretely-situated people. Conversely, while any procedure that gives some equal claimants a greater likelihood of satisfaction than others can be reasonably rejected by those who receive lesser chances, it does not seem that there is any reason for anyone to reject a fair lottery. ${ }^{20}$

It seems that all three versions of contractualism can at least permit lotteries, as they must in my view to have any plausibility. In Harsanyi's case, however, the lottery is generally taken to be unnecessary - required either simply as a means for resolving indeterminacy or only because people are happier knowing they have been given a chance. The fact that a lottery is not required by this theory is simply an instance of utilitarianism's general indifference to distributive questions and a consideration that counts against its plausibility. In contrast, I have argued that both Rawls and Scanlon offer contractualist theories that make lotteries a requirement of justice in given cases. In Scanlon's case, this is fairly obvious, for those with equal claims to a good can reasonably reject any procedure that gives them less than equal chances. In Rawls' case, the appeal to the original position may lead one to assume that it is unnecessary to implement an artificial lottery, as arbitrary natural characteristics can be appealed to instead. I have argued, however, that 'natural lotteries' are only just in cases where outcomes do not depend on identifying characteristics of individuals, as when some good literally falls randomly from the sky. It would not, however, be acceptable to attach goods to individual characteristics such as skin colour because,

19 Scanlon, op. cit., and What We Owe to Each Other (Cambridge, Mass.: Belknap Press of Harvard University Press, 1998).

20 Stone, op. cit., 291-2. C.f. Scanlon, (1998) op. cit., 232. 


\section{Ben Saunders}

although random from some hypothetical original position, they are not random from our perspective here and now. Maybe it is easier and simpler to adopt Scanlon's terminology, and say that the black person can reasonably reject discriminatory admissions, but Rawls' original position argument - when fully developed - allows us to reach the same conclusion, rejecting such practices, because parties in the original position have to consider the strains that will be placed on them by a society in which they are in fact of a certain skin colour. That lotteries are sometimes required does not, however, tell us much about in which circumstances they are required or the form that they should take.

\section{The Practice of Lotteries Reconsidered}

School places are important because places at good schools are likely to give children greater future opportunities, as well as the intrinsic benefits of education, thus their distribution is a matter of justice. ${ }^{21}$ Because education is not merely positional but an intrinsic benefit, I assume the case for levelling down is negligible. In any case, we can suppose there are no more school places than children and that in the short-term their supply is fixed, so we cannot put both children in the good school or both in the bad school. The need to send one equally-deserving child to a worse school than another is regrettable, but it is a distributional choice that we cannot avoid making.

We have seen that there are three obvious ways of distributing scarce goods - by a method of appropriate selection, by auction and by lottery. I have already suggested that the auction is implausible in this case; in any case, since the children do not have their own resources, it would come down to the 'natural lottery' of parental wealth. Further, while academic selection may have considerable merit in the case of education, if we assume we are dealing with children of average intelligence competing for places in a comprehensive school, academic selection does not look an appropriate tool. Moreover, tests are influenced by arbitrary factors such as social background, so either an auction or selection will involve a natural lottery which, I will argue, is an unfair one. The test would only be just if it gave equal applicants equal chances of selection, in which case it really would be a lottery, and we may as well have used any other arbitrary criterion, such as speed over 100 metres.

21 In this, I follow Richards, op. cit., especially 274, who argues that opportunity is a good to be distributed and promoted. 
So it seems school places should be distributed by some sort of lottery; the question is whether we need to introduce an artificial randomization or whether we can rely on some natural lottery. I earlier suggested that the chances of some natural event may be a perfectly just way of resolving the conflict between equal claims. Where we do not know which of two events is more likely to occur, we can use natural occurrences as if the heads and tails of a coin. This may, in fact, be very like a familiar lottery, for instance if two parties agree to let which way up a falling leaf lands decide their disagreement, and note again that the two events need not be objectively equiprobable, so long as we have no reason to believe either more likely. For example, a couple may agree to let the father name their child if it is a boy and the mother if it is a girl.

Sometimes we adopt rules that do not initially look like lotteries, but are in fact justified only because they are assumed to be natural lotteries. Think, for instance, of the 'first come, first served' principle. In some cases this has other justifications, for example time spent queuing could reflect need, but in general there is nothing especially meritorious about being first. In most cases, it seems the only justification for such a rule is to give every person a presumptively equal chance of receiving a good. ${ }^{22}$ Suppose we know that a piece of manna is falling from the sky, but we have no idea where it might land. We might adopt a 'finders, keepers' policy, so the first one to the scene - probably the nearest - stakes a legitimate claim to ownership. Given that, for all we know, manna is as likely to land closer to me as closer to you, this natural lottery seems perfectly just, and probably more efficient than administering another lottery of our own devising. The rule would no longer be just, however, if our expectations were different - for example, if the manna at time of discovery was obviously falling towards my land rather than yours, you could reasonably reject the principle because it gives me a greater chance of receiving the benefit to which I am no more entitled. Because where manna falls is morally arbitrary, and neither of us has greater claim to it, you may justly demand that it be allocated by a fair lottery.

The idea that school places should be allocated according to geographic proximity, when it is not either motivated by self-interest

22 I think many accepted distributive policies have, at least in part, this justification. For instance, majority rule is often defended as giving each person equal chance of satisfaction, e.g. R. Dahl Democracy and its Critics (New Haven: Yale University Press, 1989), 144 and T. Christiano, The Rule of the Many (Boulder, Colo.: Westview Press, 1996), 55. 


\section{Ben Saunders}

or supposed efficiency, is just if and only if this can be regarded as a natural lottery. If, for example, we all happened to live - permanently and immovably - in certain locations, and then schools randomly fell from the sky like manna, then the principle would indeed be a fair one, for everyone would have equal chances of living near a good or bad school. As we well know, however, this is not in fact the case. One's proximity to a good school is not a matter of chance, but depends on parental choices and, often, wealth (since house prices near to good schools tend to be inflated when such a policy is in place). To distribute school places on the basis of such a criterion is indeed arbitrary, but it is arbitrary in a predictably biased way that favours some on irrelevant grounds and that others can therefore reasonably reject.

Geographical proximity would only be fair if it was in fact a lottery that gave all equal chances of satisfaction. Since it does not do so, we need some means of distribution that does give all equal chances. While, in principle, this could still be a natural lottery - for instance, who is faster over 100 metres it is easy for discrimination based on any sort of personal characteristics to be suspected of partiality. Assigning places by the drawing of straws, names or random numbers, however, ensures complete even-handedness, making sure that every child really does have an equal chance of the good they have a claim to and none are disadvantaged by any irrelevant facts about them or their families. In short, where we have to choose which of two children should get a place in the sought-after school, it is both reasonable and just to make the selection by lottery. ${ }^{23}$

Fesus College, Oxford

23 The many debts I have incurred in thinking about related issues over the last few years are too numerous to mention here, though I must acknowledge the Arts and Humanities Research Council for supporting this earlier work. For stimulation and comments on this particular piece, I thank Conall Boyle, Robert Jubb, Peter Stone and participants in Julian Savulescu's Applied Ethics group (Oxford). 